\title{
Epidemiological Studies of Substance Dependence and Abuse in Adults
}

\author{
Erin Delker • Qiana Brown • Deborah Hasin
}

Published online: 12 February 2015

(C) Springer International Publishing AG 2015

\begin{abstract}
Drug and alcohol use disorders account for a high and potentially preventable proportion of overall disability and mortality. This article reviews published data on the distribution of alcohol and drug abuse and dependence in the USA. Published data shows that alcohol use disorders are more prevalent than illegal drug use disorders, although the persistence of both disorders was similar over a three-year follow-up period. Significant variability exists within sex, racial/ethnic, and age groups. Men, Native Americans, and young adults, aged 18 to 25 , are at a higher risk of substance dependence. Environmental correlates of disorder include early environmental factors, political environment, and social contextual factors. Systematically identifying, and measuring variability across demographic populations, will guide prevention and intervention efforts. Future research will expand
\end{abstract}

This article is part of the Topical Collection on Addictions

E. Delker • D. Hasin $(\bowtie)$

New York State Psychiatric Institute, 722 West 168th Street, New York, NY 10032, USA

e-mail: dsh2@columbia.edu

D. Hasin

e-mail: deborah.hasin@gmail.com

E. Delker

e-mail: edelker@nyspi.columbia.edu

Q. Brown · D. Hasin

Department of Epidemiology, Mailman School of Public Health, Columbia University, New York, NY 10032, USA

Q. Brown

e-mail: qb2122@columbia.edu

D. Hasin

Department of Psychiatry, Columbia University Medical Center, New York, NY 10032, USA understanding of the complex interplay between individual and environmental factors that serve to initiate and sustain alcohol and drug use disorders.

Keywords Epidemiology · Substance use · Dependence · Disorder · Abuse

\section{Introduction}

Epidemiological studies of substance use disorders (SUDs) have two primary objectives. The first is to describe the distribution of disorder within populations, including prevalence, incidence, and persistence. The second is to identify determinants and risk factors for SUDs and related health outcomes in populations. In the USA, SUDs are defined by the Diagnostic and Statistical Manual of Mental Disorders (DSM). Table 1 details diagnostic criteria for DSM-IV substance abuse and DSM-IV substance dependence [1•]. This review provides an overview of recent findings from nationally representative samples on the distribution of alcohol and substance abuse and dependence. In addition, we present correlates of substance abuse and dependence (e.g., sex, race, age, and environmental correlates).

\section{Sources of Information}

Much of the information in this review was derived from two US national general population surveys: the National Epidemiologic Survey on Alcohol and Related Conditions (NESARC), and the National Survey on Drug Use and Health 
Table 1 Diagnostic Criteria for DSM-IV Substance Use Disorders

\begin{tabular}{lll}
\hline Diagnostic Criteria & Abuse & Dependence \\
\hline Craving/strong desire/urge to use a specific substance & - & - \\
Tolerance & - & $\mathrm{X}$ \\
Withdrawal* & - & $\mathrm{X}$ \\
Persistent desire/unsuccessful efforts to cut down/control use & - & $\mathrm{X}$ \\
Using in larger amounts/over a longer period than intended & - & $\mathrm{X}$ \\
Neglect of important activities because of substance use & - & $\mathrm{X}$ \\
Great deal of time spent in substance-related activities & - & $\mathrm{X}$ \\
Continued use despite substance-related physical/psychological problems & $\mathrm{X}$ & $\mathrm{X}$ \\
Recurrent substance use resulting in a failure to fulfill major role obligations & $\mathrm{X}$ & - \\
Recurrent use in situations in which it is physically hazardous & $\mathrm{X}$ & - \\
Recurrent substance-related legal problems & $\mathrm{X}$ & - \\
Continued use despite persistent or recurrent substance-related problems & $1+$ criteria \\
Threshold for diagnosis & - \\
\hline
\end{tabular}

*Marijuana and hallucinogen use disorders do not include the withdrawal criterion

Source: Hasin et al. (2013)

(NSDUH). The NESARC, funded by the National Institute of Alcohol Abuse and Alcoholism (NIAAA) with supplemental funding from the National Institute of Drug Abuse (NIDA), is a two-wave, longitudinal study. Wave 1 (2001-2002), and Wave 2 (2004-2005) data are used to study the epidemiology of substance use disorders, psychiatric disorders and healthrelated conditions $[2,3]$. The study utilizes the intervieweradministered Alcohol Use Disorder and Associated Disabilities Interview Schedule- DSM-IV Version (AUDADIS-IV) [4-7], which has been subjected to extensive psychometric testing in the general population and clinical samples [4-8]. The NSDUH is an annual survey of respondents aged 12 years and older, funded by the Substance Abuse and Mental Health Services Administration (SAMHSA). The survey is primarily used to monitor trends in substance use and other psychiatric variables. NSDUH respondents report data via selfadministered computerized interviews [9].

\section{Population Distribution of Substance Use and Dependence}

\section{Alcohol}

Table 2 provides information from the NESARC on prevalence of past year alcohol abuse, dependence, and any alcohol use disorder (AUD). In the NESARC Wave 1 sample, $4.7 \%$ of respondents met DSM-IV criteria for a diagnosis of past year alcohol abuse and $3.8 \%$ for past year alcohol dependence $[10,11]$. Lifetime prevalence estimates in the same sample were $17.8 \%$ for alcohol abuse and $12.5 \%$ for alcohol dependence [10]. In the $2012 \mathrm{NSDUH}$ data, $3.3 \%$ of respondents reported symptoms and criteria indicating past year DSM-IV alcohol dependence, and 3.5\% met criteria for past year DSM-IV alcohol abuse [12].

The two-wave study design of the NESARC enables researchers to provide estimates of incidence and persistence of AUDs. Over a three-year period, past year incidence of alcohol abuse and alcohol dependence was $1.0 \%$ and $1.7 \%$, respectively [3]. Further, among individuals with DSM-IV dependence at Wave 1, 30.1 \% of cases persisted at full symptom level at Wave 2 [13]. Among respondents with alcohol dependence at Wave 1, 5.4\% reported past year abstinence (abstinent recovery), and $5.5 \%$ drank but did not endorse any DSM-IV alcohol dependence or abuse symptoms in past year (non-abstinent recovery), at Wave 2 [14•]. Helpseeking, including participation in 12-step programs and formal treatment, increased the likelihood of recovery from

Table 2 Past-year prevalence of use disorder abuse and dependence among NESARC respondents

Past Year Prevalence (\%)

\begin{tabular}{llll}
\hline & Use disorder & Abuse & Dependence \\
Alcohol & 8.50 & 4.65 & 3.81 \\
Any Illicit drug & 2.00 & 1.37 & 0.63 \\
Marijuana and hashish & 1.45 & 1.13 & 0.32 \\
Cocaine & 0.27 & 0.13 & 0.13 \\
Opioid & 0.23 & 0.24 & 0.11 \\
Hallucinogens & 0.14 & 0.12 & 0.02 \\
Inhalants & 0.00 & 0.02 & 0.00 \\
Sedatives & 0.16 & 0.09 & 0.07 \\
Tranquilizer & 0.13 & 0.08 & 0.05 \\
Amphetamine & 0.16 & 0.09 & 0.07 \\
\hline
\end{tabular}


alcohol dependence with an onset at least 12 months prior to the interview [15].

\section{Illicit Drugs}

Table 2 provides information from the NESARC on prevalence of past year DSM-IV substance abuse, dependence, and any DSM-IV SUD. In the NESARC Wave 1 sample, $1.4 \%$ and $0.63 \%$ of respondents met DSM-IV criteria for any past year drug abuse and past year dependence. Also, $7.7 \%$ and $3.6 \%$ of respondents met criteria for any lifetime drug abuse and lifetime dependence [16]. In the 2012 NSDUH data, $1.8 \%$ of respondents reported symptoms and criteria of past year DSM-IV illicit drug dependence, and $0.8 \%$ reported past year alcohol abuse [12]. In comparing NESARC and NSDUH estimates, the differences in abuse and dependence prevalence estimates may be real, or may be due to discrepancies in measurement and study design [11]. Information is not available to determine this.

In the NESARC sample, $30.9 \%$ of respondents with an SUD at Wave 1 endorsed symptoms and criteria for an SUD at Wave $2[17 \cdot]$. Of these persistent cases, $85.7 \%$ of individuals met criteria for the same substance specific disorder at both waves, while $14.3 \%$ of respondents did not [17•]. The incidence of illicit drug use between Wave 1 and Wave 2 was low among non-users. At Wave 2, $2.1 \%$ of non-users at baseline initiated use, and $2.5 \%$ of non-users at baseline initiated problem use. Among asymptomatic users at baseline, 19.1\% became problem users [18]. Prevalence estimates for substance use disorder were highest for cannabis, cocaine, and heroin [16].

\section{Cannabis}

Among the illicit drugs, cannabis had the highest prevalence of past year use DSM-IV disorder (1.45\%), abuse $(1.13 \%)$, and dependence $(0.32 \%)$, compared to other illicit drugs in the NESARC Wave 1 sample [16]. Also, $31.5 \%$ of the respondents with cannabis use disorder at Wave 1 persisted to Wave 2 [17•]. In the 2012 NSDUH sample, $1.7 \%$ of respondents reported past year cannabis use disorder [12]. Prevalence of cannabis use disorder among individuals with lifetime exposure to cannabis, defined as "either without a doctor's prescription, in greater amounts, more often or longer than prescribed; or for a reason other than a doctor said you should use them," is $6.3 \%$ [19].

\section{Cocaine}

In the NESARC Wave 1 sample, $0.27 \%, 0.13 \%$ and $0.13 \%$ of respondents met DSM-IV criteria for cocaine use disorder, abuse, and dependence, respectively [16]. The NSDUH estimate of cocaine use disorder in the same year (2001) was
$0.6 \%$ [11]. In the 2012 NSDUH sample, $0.4 \%$ of respondents reported past year cocaine use disorder [12]. Among NESARC respondents with lifetime exposure to cocaine, $45.7 \%$ developed a cocaine use disorder [19]. Among NESARC respondents with a lifetime diagnosis of cocaine dependence, the cumulative probabilities of remission after onset within the first year, within five years, and within a decade were $8.6 \%, 50.0 \%$, and $75.8 \%$, respectively [20].

Heroin

In the NESARC Wave 1 sample, $0.4 \%, 0.2 \%$ and $0.1 \%$ of respondents met criteria for DSM-IV opioid use disorder, opioid abuse, and opioid dependence [21]. When assessed separately from opioids in general, $0.2 \%$ of the NESARC Wave 1 Sample met criteria for heroin use disorder [11]. In the 2012 NSDUH sample, $0.2 \%$ of respondents endorse criteria for a heroin use disorder [12]. Among individuals with lifetime heroin use in the NESARC sample, prevalence of past year DSM-IV abuse and past year dependence were $63 \%$ and $28 \%[19,22]$. The average time between first heroin use and onset of abuse was 1.5 years, and the average time between first use and onset of dependence was 2.0 years [22]. Of the abuse cases $94 \%$ remitted, compared to $96 \%$ of dependence cases [22].

\section{Nonmedical Use of Prescription Drugs}

Past year nonmedical prescription drug abuse and dependence has increased over the past two decades [23, 24]. In the 2012 NSDUH sample, $1.0 \%$ of respondents endorsed symptoms and criteria for an SUD via nonmedical use of prescription drugs [12]. Prevalence of substance use disorders from nonmedical use of prescription drugs are: pain relievers $0.8 \%$, tranquilizers $0.2 \%$, stimulants $0.2 \%$, and sedatives $0.1 \%$ [12]. Among nonmedical prescription opioid users in the NESARC sample, $22.8 \%$ endorsed criteria for abuse and $7.2 \%$ for dependence [22]. The mean intervals from first use to abuse onset and from first use to dependence onset were 2.6 years and 2.9 years, respectively [22].

\section{Correlates of Substance Dependence in the USA}

Sex

Compared to women, men have an increased risk of developing alcohol dependence (Fig. 1) $[25,26]$. In the NESARC Wave 1 sample, the prevalence of current alcohol dependence among men (5.4\%) was higher than women (2.3\%) [23]. Additionally, men were twice as likely to develop incident alcohol dependence $(\mathrm{OR}=2.4)$, and incident alcohol abuse 

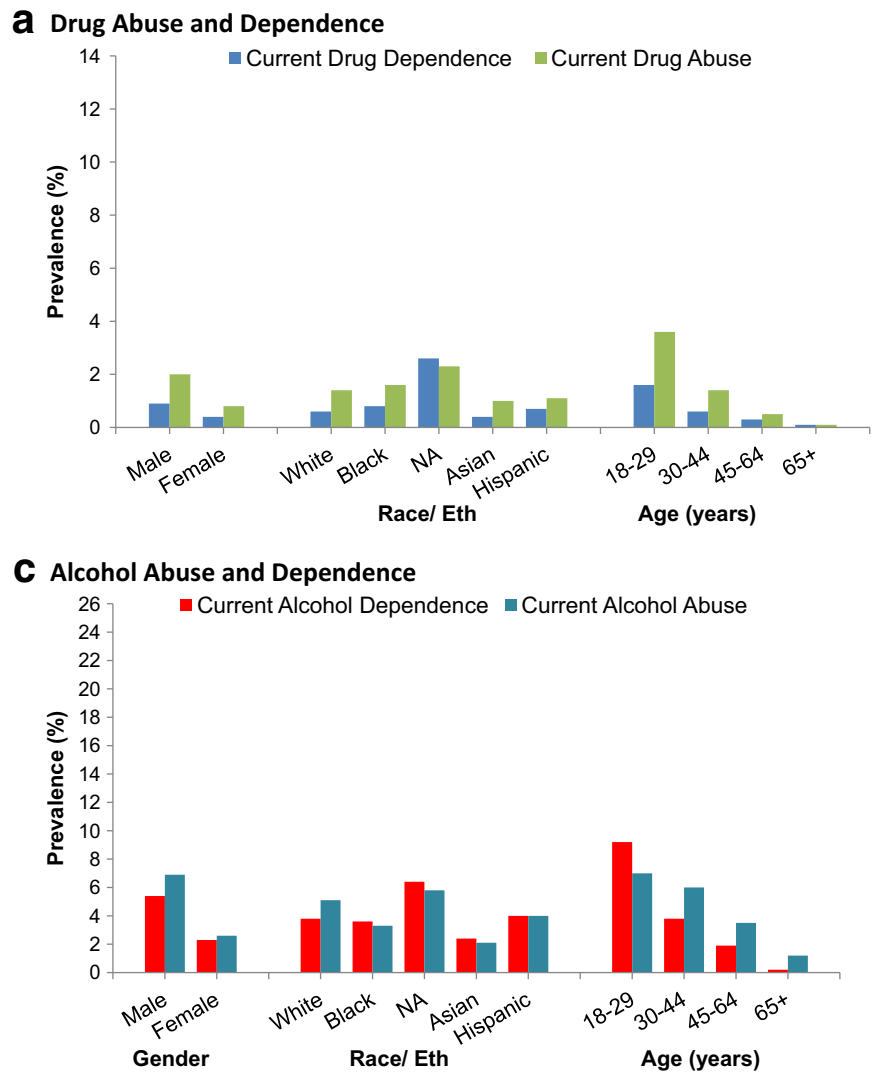

b Drug Abuse and Dependence

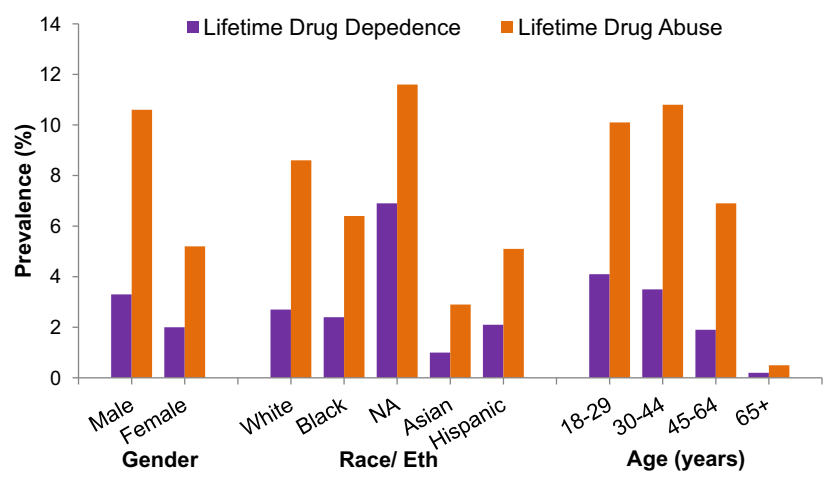

d Alcohol Abuse and Dependence

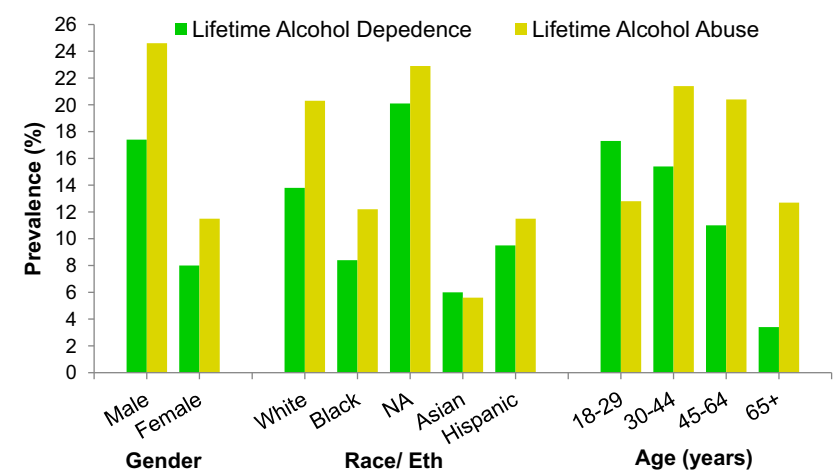

Fig. 1 a Current drug dependence and abuse; b Lifetime drug dependence and abuse; c Current alcohol dependence and abuse; d Lifetime alcohol dependence and abuse

$(\mathrm{OR}=2.3)$, between Waves 1 and 2 of the NESARC [3], Often, clinicians consider alcohol disorders among women to be "telescoped." This phenomenon is defined as women having a later onset of use, and therefore a shorter interval between first use and dependence. However, a study using NESARC data shows little evidence for this phenomenon [27]. More recently, Keyes et al. (2010), used evidence from NESARC and NLAES to again show that women do not have a shorter time to dependence and first treatment [28].

Similar to alcohol, men report higher prevalence of drug dependence than women (Fig. 1) [21]. In the NESARC Wave 1 sample, men reported higher prevalence of past year SUD and lifetime SUD (2.8\% and $13.8 \%)$ than women (1.2\% and $7.1 \%$ ) [21]. In the 2012 NSDUH sample, men reported higher SUD (3.8\%) of illicit drugs compared to women (1.9\%) [12]. Between NESARC Wave 1 and Wave 2, men were more likely to develop incident drug dependence [3]. Among individuals with lifetime use of specific substances, odds of meeting criteria for an SUD were significantly higher among men compared to women for sedatives $(\mathrm{OR}=2.0)$, and cannabis $(\mathrm{OR}=1.9)$, but not other drugs [19]. Further, one study reports that women have greater rates of cocaine dependence [29]. Information on the "telescoping" phenomenon is not available for drugs in the NESARC or NSDUH samples. In a clinical sample of substance-dependent patients, women reported fewer years of regular alcohol, opioid, and cannabis use before entering substance abuse treatment [30]. More information on this is needed in the general population.

\section{Race/Ethnicity}

The prevalence of current and lifetime alcohol use disorders, including abuse and dependence, varies by race (Fig. 1). In the NESARC data, $6.4 \%$ of Native Americans, $4.0 \%$ of Hispanics, $3.8 \%$ of Whites, $3.6 \%$ of Blacks and $2.4 \%$ of Asians met criteria for past year DSM-IV alcohol dependence [23]. One study finds no significant difference by race for incident alcohol dependence between NESARC Wave 1 and 2. However, risk of incident alcohol abuse was lowest among Blacks, compared to Whites and Hispanics [3].

Asians report the lowest prevalence of drug abuse/dependence, whereas Native Americans/ Alaska Natives report the highest (Fig. 1). In 2013, the prevalence of past year drug use disorders, including abuse or dependence, was $3.6 \%$ for Native American/ Alaska Natives, 3.5\% for respondents identifying as two or more races, $2.2 \%$ for Blacks, $1.6 \%$ for Whites, $1.5 \%$ for Hispanics and $0.8 \%$ for Asians [9]. However, race/ethnic groups did not differ in the odds of developing an incident drug use disorder between NESARC Wave 1 and 2 [3]. Past year incidence of any drug abuse and 
dependence was $0.4 \%$ and $0.3 \%$ among Hispanics, $0.3 \%$ and $0.3 \%$ among Whites, and $0.2 \%$ and $0.4 \%$ among Blacks. Lack of significant findings may result from limitations in sample size [3]. In the NESARC sample, Native Americans had significantly higher odds of lifetime nonmedical prescription drug use disorder than all other groups. Compared to Whites, Native Americans have 3.2 times higher odds of sedative disorder, 3.4 times higher odds of tranquilizer disorder, 2.9 times higher odds of opioid disorder and 2.2 times higher odds of amphetamine disorder. Being Black, Asian or Hispanic was protective against all four categories of drug use disorders relative to Whites [31].

\section{Age}

Prevalence and incidence of alcohol dependence and abuse decrease with age $[23,32]$. In the NESARC, incident alcohol dependence in Wave 2 was most prevalent among 20 to 29year olds and 30 to 54-year olds [23]. Similarly, prevalence of alcohol abuse peaks between ages 18 to 24 and ages 25 to 34 [33]. AUD prevalence was lowest among the people 65 years and older [23]. Risk for alcohol dependence and abuse continues to decrease beyond ages 75 and 85 (Fig. 1) [33, 34].

In the 2013 NSDUH sample, young adults aged 18 to 25 had the highest prevalence dependence/abuse across all drug categories [9]. Among respondents aged 18 to 25 years, the prevalence of cannabis use disorder (5.4\%), was higher than respondents older than age $26(0.8 \%)$ [9]. In the same sample, past year disorder for illicit drugs was $0.3 \%$ and $11.7 \%$ among users aged 50 years and older [35]. A cross-sectional analysis of the NESARC sample presents lifetime nonmedical prescription drug disorder prevalence by age group (18-29 years, 30-44 years, 45-64 years, and 65+ years). Aging adults $(65+$ years $)$, reported the lowest prevalence of lifetime disorder of sedatives $(0.1 \%)$, tranquilizers $(0.1 \%)$, opioids $(0.2 \%)$, and amphetamines $(0.1 \%)$ [31].

Additionally, age of first use is a significant risk factor for subsequent substance use disorders. In the NESARC, respondents who began drinking before age 14 had the highest prevalence of lifetime and past year alcohol dependence [36]. Further, illicit drug users with adolescent-onset are at increased risk of developing drug dependence [9]. Mean age of first use for specific substances are: heroin, 21.8 years [22]; nonmedical prescription opioid users, 23.2 years [22]; and cannabis, 19 years [37].

\section{Environmental Correlates}

Early environmental factors, such as aspects of the childhood environment are associated with the long-term risk for later development of SUDs. For example, in the NESARC, parental divorce and separation were significantly correlated with adult lifetime alcohol dependence. This relationship maintains despite adjusting for parental history of substance use and depression [38]. In addition, the larger the number of childhood traumatic experiences, the higher the risk of adult alcohol dependence [39]. Furthermore, the magnitude of childhood maltreatment has a direct effect on risk of alcohol persistence between NESARC Wave 1 and Wave 2 [40]. Also, in the NESARC sample, childhood adversity was associated with increased risk for past year cannabis use disorders and opiate disorders [41].

The policy environment, such as taxation and constraints or permissiveness regarding legal substance use may affect the risk for substance abuse and disorder. In a NESARC study of individuals who had entered the age at risk for initiation of alcohol use during an era when the minimum legal drinking age varied by state showed that those who were legally able to purchase alcohol before age 21 had higher risk of AUD $(O R=$ 1.31), and SUD $(\mathrm{OR}=1.70)$, throughout their lives than individuals not legally able to purchase alcohol at that age [42]. Further, taxes and beverage alcohol prices have an inverse relationship with alcohol dependence [43], and heavy drinking [44]. Moreover, a recent study found that smoke-free policies in drinking venues is associated with a lower likelihood of AUDs among smokers [45].

Social contextual factors, such as neighborhood stressors (poverty, crime, and violence), contribute to increased risk of drug use and dependence. In addition, alcohol availability is significantly associated with neighborhood stress and risk of alcohol related harmful consequences [46]. Numerous other factors can also be considered contextual, for example, religiosity, which has been regarded as protective against drug and alcohol use and dependence [47, 48]. Teasing out the causal direction between education and risk for SUD is difficult, but in the NESARC, risk for alcohol dependence was significantly higher for people without a college degree compared to those with a college degree or higher [49]. In addition, individuals with past year diagnosis of AUDs reported less diverse, and smaller, social networks [50].

Incidence of drug dependence between NESARC Wave 1 and 2 was highest among respondents that were separated, divorced, or widowed compared to those who had never married or remained married [3]. Similarly, incidence of alcohol dependence between NESARC Wave 1 and 2 was highest among never married and separated, divorced, or widowed compared to married, or living with someone as married groups [3]. Stressful life events in adulthood (e.g., marital separation, being unemployed, financial crisis, unexpected death of family member or close friend), have been associated with increased risk for cannabis, stimulant, and opiate use disorders among men, and cannabis and opiate use disorders among women [41]. Whether the stressful events were the causes or consequences of the SUDs cannot be discerned from cross-sectional studies. The direction of effect between several risk factors that 
can be considered to be contextual, and the risk for AUD and SUD is difficult to determine, as the associations may be due to common underlying factors. This is an important area of future research.

\section{Conclusions}

Large national studies offer valuable data on the epidemiology of SUDs in the USA. Varying methodology, as exemplified in the NSDUH and NESARC, may limit comparison and interpretation of estimates between epidemiological studies. Nevertheless, epidemiologic surveys present a valid depiction of SUDs, and can provide important information necessary to develop evidence-based measures to prevent the onset of substance SUDs and co-morbidity, as well as identify factors that increase the risk of alcohol and drug problems.

Although this review was based on studies using DSM-IV diagnostic criteria for abuse and dependence, advances in the measurement of substance use disorders are reflected in a new version published in 2013, DSM-5. The DSM-5 no longer provides criteria for substance abuse and dependence. Instead, substance use disorder, with three levels of severity (mild, moderate and severe), is diagnosed based on number of criteria met by an individual. The shift to Arabic numerals in DSM-5 is a departure from the traditional use of roman numerals applied in previous versions of the manual. This change in nomenclature will clearly denote any future changes to the criteria (e.g., DSM-5.1; DSM-5.2). This change will allow for more responsive adjustments to the DSM when future research elucidates ways to improve diagnoses [1•].

In 2012-2013, a new NESARC survey (NESARC-III), was conducted with a sample of new respondents aged 18 and older. Findings from NESARC-III will be forthcoming over the next year and will provide information on the extent of DSM-5defined SUDs in the population, estimate the size and characteristics of populations of special concern, and determine and describe treatment utilization for AUD and SUD. In addition, NESARC-III will obtain information necessary to determine the economic impact of AUDs via impaired productivity in the workplace. Lastly, NESARC-III will provide invaluable information on genetic variants, which will increase understanding of the complex interplay between genetic and environmental factors that serve to initiate and sustain alcohol and drug use disorders and their associated disabilities.

In the USA, AUDs and SUDs account for a high and potentially preventable proportion of overall disability and mortality. Further, there is significant variation between important population subgroups on the burden of disease and its consequences. The myriad of genetic, social, and environmental risk factors for alcohol and drug use disorders remain to be elucidated. Future epidemiologic studies will provide important information necessary to prevent and treat alcohol and drug use disorders by identifying factors that increase the risk of these disorders and their persistence in the general population.

\section{Compliance with Ethics Guidelines}

Conflict of Interest Erin Delker, Qiana Brown and Deborah Hasin have no conflicts of interest.

Human and Animal Rights and Informed Consent This article does not contain any studies with human or animal subjects performed by any of the authors.

\section{References}

Papers of particular interest, published recently, have been highlighted as:

- Of importance

1. Hasin DS, O'Brien CP, Auriacombe M, Borges G, Bucholz K, Budney A, et al. DSM-5 criteria for substance use disorders: recommendations and rationale. Am J Psychiatry. 2013;170(8):83451. This article presents empirical evidence that the DSM-5 Substance-Related Disorders Work Group considered in their recommendations for revising the DSM substance abuse and dependence diagnoses. The DSM-5 revisions, including comibing abuse and dependence into one use disorder diagnosis, adding craving critera and dropping legal problems as a criteria will resolve previously identified methodological problems with the DSM-IV diagnoses. The revisions also establish a new diagnostic framework to guide future research.

2. Grant BF, Hasin DS, Stinson FS, Dawson DA, Chou SP, Ruan WJ, et al. Prevalence, correlates, and disability of personality disorders in the USA: results from the national epidemiologic survey on alcohol and related conditions. J Clin Psychiatry. 2004;65(7):948-58.

3. Grant BF, Goldstein RB, Chou SP, Huang B, Stinson FS, Dawson DA, et al. Sociodemographic and psychopathologic predictors of first incidence of DSM-IV substance use, mood and anxiety disorders: results from the Wave 2 National Epidemiologic Survey on Alcohol and Related Conditions. Mol Psychiatry. 2009;14(11):1051-66.

4. Grant BF, Harford TC, Dawson DA, Chou PS, Pickering RP. The alcohol use disorder and associated disabilities interview schedule (AUDADIS): reliability of alcohol and drug modules in a general population sample. Drug Alcohol Depend. 1995;39(1):37-44.

5. Hasin D, Carpenter KM, McCloud S, Smith M, Grant BF. The alcohol use disorder and associated disabilities interview schedule (AUDADIS): reliability of alcohol and drug modules in a clinical sample. Drug Alcohol Depend. 1997;44(2-3):133-41.

6. Grant BF, Dawson DA, Stinson FS, Chou PS, Kay W, Pickering R. The alcohol use disorder and associated disabilities interview schedule-IV (AUDADIS-IV): reliability of alcohol consumption, tobacco use, family history of depression and psychiatric diagnostic modules in a general population sample. Drug Alcohol Depend. 2003;71(1):7-16.

7. Ruan WJ, Goldstein RB, Chou SP, Smith SM, Saha TD, Pickering $\mathrm{RP}$, et al. The alcohol use disorder and associated disabilities interview schedule-IV (AUDADIS-IV): reliability of new psychiatric diagnostic modules and risk factors in a general population sample. Drug Alcohol Depend. 2008;92(1-3):27-36. 
8. Grant BF. Prevalence and correlates of alcohol use and DSM-IV alcohol dependence in the USA: results of the National Longitudinal Alcohol Epidemiologic Survey. J Stud Alcohol. 1997;58(5):464-73.

9. (SAMHSA) SAaMHSA. Results from the 2013 National Survey on Drug Use and Health: National findings. Rockville, MD 2014.

10. Hasin DS, Stinson FS, Ogburn E, Grant BF. Prevalence, correlates, disability, and comorbidity of DSM-IV alcohol abuse and dependence in the USA: results from the National Epidemiologic Survey on Alcohol and Related Conditions. Arch Gen Psychiatry. 2007;64(7):830-42.

11. Grucza RA, Abbacchi AM, Przybeck TR, Gfroerer JC. Discrepancies in estimates of prevalence and correlates of substance use and disorders between two national surveys. Addiction. 2007;102(4):623-9.

12. (SAMHSA) SAaMHSA. Results from the 2012 National Survey on Drug Use and Health: National findings. Rockville, MD 2013.

13. Hasin D, Fenton MC, Skodol A, Krueger R, Keyes K, Geier T, et al. Personality disorders and the 3-year course of alcohol, drug, and nicotine use disorders. Arch Gen Psychiatry. 2011;68(11):1158-67.

14. Dawson DA, Goldstein RB, Ruan WJ, Grant BF. Correlates of recovery from alcohol dependence: a prospective study over a 3year follow-up interval. Alcohol Clin Exp Res. 2012;36(7):126877. This paper identifies socio-demographic and clinical correlates of recovery from past year DSM-IV Alcohol Dependence. Significant correlates include marital status, employment, smoking status, and past year average daily ethanol (EtOH) intake.

15. Dawson DA, Grant BF, Stinson FS, Chou PS. Estimating the effect of help-seeking on achieving recovery from alcohol dependence. Addiction. 2006;101(6):824-34.

16. Grant BF, Stinson FS, Dawson DA, Chou SP, Dufour MC, Compton W, et al. Prevalence and co-occurrence of substance use disorders and independent mood and anxiety disorders: results from the National Epidemiologic Survey on Alcohol and Related Conditions. Arch Gen Psychiatry. 2004;61(8):807-16.

17. Fenton MC, Keyes K, Geier T, Greenstein E, Skodol A, Krueger B, et al. Psychiatric comorbidity and the persistence of drug use disorders in the United States. Addiction. 2012;107(3):599-609. This article is the first to examine the prevalence of three-year persistence of drug use disorders in a nationally representative sample. The authors also consider persistence in the context of mood, anxiety, alcohol, nicotine and DSM-IV personality disorders.

18. Compton WM, Dawson DA, Conway KP, Brodsky M, Grant BF. Transitions in illicit drug use status over 3 years: a prospective analysis of a general population sample. Am J Psychiatry. 2013;170(6):660-70.

19. Lev-Ran S, Le Strat Y, Imtiaz S, Rehm J, Le Foll B. Gender differences in prevalence of substance use disorders among individuals with lifetime exposure to substances: results from a large representative sample. Am J Addict. 2013;22(1):7-13.

20. Lopez-Quintero C, Hasin DS, de Los Cobos JP, Pines A, Wang S, Grant BF, et al. Probability and predictors of remission from lifetime nicotine, alcohol, cannabis or cocaine dependence: results from the National Epidemiologic Survey on Alcohol and Related Conditions. Addiction. 2011;106(3):657-69.

21. Compton WM, Thomas YF, Stinson FS, Grant BF. Prevalence, correlates, disability, and comorbidity of DSM-IV drug abuse and dependence in the USA: results from the national epidemiologic survey on alcohol and related conditions. Arch Gen Psychiatry. 2007;64(5):566-76.

22. Wu LT, Woody GE, Yang C, Mannelli P, Blazer DG. Differences in onset and abuse/dependence episodes between prescription opioids and heroin: results from the National Epidemiologic Survey on Alcohol and Related Conditions. Subst Abuse Rehabil. 2011;2011(2):77-88.
23. Blanco C, Alderson D, Ogburn E, Grant BF, Nunes EV, Hatzenbuehler ML, et al. Changes in the prevalence of non-medical prescription drug use and drug use disorders in the USA: 1991-1992 and 2001-2002. Drug Alcohol Depend. 2007;90(2-3):252-60.

24. Manchikanti L, Helm 2nd S, Fellows B, Janata JW, Pampati V, Grider JS, et al. Opioid epidemic in the USA. Pain Physician. 2012;15(3 Suppl):ES9-38.

25. Alvanzo AA, Storr CL, La Flair L, Green KM, Wagner FA, Crum RM. Race/ethnicity and sex differences in progression from drinking initiation to the development of alcohol dependence. Drug Alcohol Depend. 2011;118(2-3):375-82.

26. Sharon C. Wilsnack PDRWW, Ph.D.; and Lori Wolfgang Kantor, M.A. Focus On: Women and the Costs of Alcohol Use: NIAAA; 2013.

27. Keyes KM, Grant BF, Hasin DS. Evidence for a closing gender gap in alcohol use, abuse, and dependence in the US population. Drug Alcohol Depend. 2008;93(1-2):21-9.

28. Keyes KM, Martins SS, Blanco C, Hasin DS. Telescoping and gender differences in alcohol dependence: new evidence from two national surveys. Am J Psychiatry. 2010;167(8):969-76.

29. Cotto JH, Davis E, Dowling GJ, Elcano JC, Staton AB, Weiss SR. Gender effects on drug use, abuse, and dependence: a special analysis of results from the National Survey on Drug Use and Health. Gend Med. 2010;7(5):402-13.

30. Hernandez-Avila CA, Rounsaville BJ, Kranzler HR. Opioid-, cannabis- and alcohol-dependent women show more rapid progression to substance abuse treatment. Drug Alcohol Depend. 2004;74(3):265-72.

31. Huang B, Dawson DA, Stinson FS, Hasin DS, Ruan WJ, Saha TD, et al. Prevalence, correlates, and comorbidity of nonmedical prescription drug use and drug use disorders in the USA: Results of the National Epidemiologic Survey on Alcohol and Related Conditions. J Clin Psychiatry. 2006;67(7):1062-73.

32. Dawson DA, Li TK, Chou SP, Grant BF. Transitions in and out of alcohol use disorders: their associations with conditional changes in quality of life over a 3-year follow-up interval. Alcohol. 2009;44(1):84-92.

33. Rehm J, Dawson D, Frick U, Gmel G, Roerecke M, Shield KD, et al. Burden of disease associated with alcohol use disorders in the USA. Alcohol Clin Exp Res. 2014;38(4):1068-77.

34. Moore AA, Karno MP, Grella CE, Lin JC, Warda U, Liao DH, et al. Alcohol, tobacco, and nonmedical drug use in older US Adults: data from the 2001/02 national epidemiologic survey of alcohol and related conditions. J Am Geriatr Soc. 2009;57(12):2275-81.

35. Han B, Gfroerer JC, Colliver JD, Penne MA. Substance use disorder among older adults in the USA in 2020. Addiction. 2009;104(1):88-96.

36. Hingson RW, Heeren T, Winter MR. Age at drinking onset and alcohol dependence: age at onset, duration, and severity. Arch Pediatr Adolesc Med. 2006;160(7):739-46.

37. Stinson FS, Ruan WJ, Pickering R, Grant BF. Cannabis use disorders in the USA: prevalence, correlates and co-morbidity. Psychol Med. 2006;36(10):1447-60.

38. Thompson Jr RG, Lizardi D, Keyes KM, Hasin DS. Childhood or adolescent parental divorce/separation, parental history of alcohol problems, and offspring lifetime alcohol dependence. Drug Alcohol Depend. 2008;98(3):264-9.

39. Pilowsky DJ, Keyes KM, Hasin DS. Adverse childhood events and lifetime alcohol dependence. Am J Public Health. 2009;99(2):258-63.

40. Elliott JC, Stohl M, Wall MM, Keyes KM, Goodwin RD, Skodol $\mathrm{AE}$, et al. The risk for persistent adult alcohol and nicotine dependence: the role of childhood maltreatment. Addiction. 2014;109(5): $842-50$.

41. Myers B, McLaughlin KA, Wang S, Blanco C, Stein DJ. Associations between childhood adversity, adult stressful life events, and past-year drug use disorders in the National 
Epidemiological Study of Alcohol and Related Conditions (NESARC). Psychol Addict Behav 2014.

42. Norberg KE, Bierut LJ, Grucza RA. Long-term effects of minimum drinking age laws on past-year alcohol and drug use disorders. Alcohol Clin Exp Res. 2009;33(12):2180-90.

43. Henderson C, Liu X, Diez Roux AV, Link BG, Hasin D. The effects of US state income inequality and alcohol policies on symptoms of depression and alcohol dependence. Soc Sci Med. 2004;58(3):565-75.

44. Wagenaar AC, Salois MJ, Komro KA. Effects of beverage alcohol price and tax levels on drinking: a meta-analysis of 1003 estimates from 112 studies. Addiction. 2009;104(2): 179-90.

45. Young-Wolff KC, Hyland AJ, Desai R, Sindelar J, Pilver CE, McKee SA. Smoke-free policies in drinking venues predict transitions in alcohol use disorders in a longitudinal US sample. Drug Alcohol Depend. 2013;128(3):214-21.
46. Stockdale SE, Wells KB, Tang L, Belin TR, Zhang L, Sherbourne $\mathrm{CD}$. The importance of social context: neighborhood stressors, stress-buffering mechanisms, and alcohol, drug, and mental health disorders. Soc Sci Med. 2007;65(9):1867-81.

47. Chou KL, Liang K, Sareen J. The association between social isolation and DSM-IV mood, anxiety, and substance use disorders: wave 2 of the National Epidemiologic Survey on Alcohol and Related Conditions. J Clin Psychiatry. 2011;72(11):1468-76.

48. Koenig HG, King DE, Carson VB. Handbook of religion and health 2nd ed. Oxford: Oxford University Press, Inc.; 2012.

49. Gilman SE, Breslau J, Conron KJ, Koenen KC, Subramanian SV, Zaslavsky AM. Education and race-ethnicity differences in the lifetime risk of alcohol dependence. J Epidemiol Community Health. 2008;62(3):224-30.

50. Mowbray O, Quinn A, Cranford JA. Social networks and alcohol use disorders: findings from a nationally representative sample. Am J Drug Alcohol Abuse. 2014;40(3):181-6. 